\title{
La sociedad por acciones simplificada (SAS) y su desenvolvimiento en la jurisdicción de la provincia de La Pampa
}

\author{
Eduardo Pordomingo \\ Universidad Nacional de La Pampa, \\ Facultad de Ciencias Económicas y Jurídicas, Santa Rosa, Argentina \\ \eddiex10@gmail.com \\ Anabela Evangelista \\ Universidad Nacional de La Pampa, \\ Facultad de Ciencias Económicas y Jurídicas, Santa Rosa, Argentina \\ $\bigotimes$ anaevangelista83@gmail.com \\ Mauricio Gabriel Villa \\ Universidad Nacional de La Pampa, \\ Facultad de Ciencias Económicas y Jurídicas, Santa Rosa, Argentina \\ $\bigotimes$ mauriciogabrielvilla@gmail.com \\ 㖰) Fecha de recepción: 27/06/2021 - Fecha de aceptación: 21/09/2021
}

Cómo citar este artículo: Pordomingo, E.; Evangelista, A.; Villa, M. (2022). La sociedad por acciones simplificada (SAS) y su desenvolvimiento en la jurisdicción de la provincia de La Pampa. Revista Perspectivas de las Ciencias Económicas y Jurídicas. Vol. 12, $\mathrm{N}^{\circ} 1$ (enero-junio). Santa Rosa: FCEyJ (UNLPam); EdUNLPam; pp. 133-158. ISSN 2250-4087, e-ISSN 2445856. http://dx.doi.org/10.19137/perspectivas-2022-v12n1a09

Resumen: El marco legal que ofrece la Ley 27.349 de Apoyo al Capital Emprendedor (LACE) constituye una alternativa idónea para canalizar pequeños y medianos emprendimientos en la jurisdicción de la provincia de La Pampa. La figura de la sociedad por acciones simplificada (SAS) ha 
adquirido cierta preponderancia por encima de otros tipos sociales regulados por la Ley 19.550 General de Sociedades (LGS). Los aspectos centrales que motivan o favorecen su aplicación en la práctica mercantil refieren a la posibilidad de separar patrimonios, la limitación de la responsabilidad, la posibilidad de afectar patrimonios unipersonales, la separación de actividades y la simplificación de los trámites registrales y administrativos en su funcionamiento.

Esta cuestión se encuentra en la actualidad planteada en el proyecto de reforma de la ley que regula las SAS y que ya cuenta con media sanción del Senado de la Nación. Entre las modificaciones propuestas se encuentran las siguientes: la inscripción por parte de los emprendedores en un registro específico, el traspaso del registro digital a la autoridad de contralor para su administración, el control y mantenimiento exclusivo, la obligación de presentar los estados contables y la aplicación en forma supletoria de las disposiciones de la LGS.

Palabras clave: sociedad por acciones simplificada (SAS); motivaciones para la constitución; control de legalidad; autonomía de la voluntad.

\section{The simplified joint stock company (SAS) and its development in the jurisdiction of the province of La Pampa}

Abstract: The legal framework offered by law 27.349 constitutes a good alternative to channel small and medium-sized enterprises in the jurisdiction of the province of La Pampa. The figure of the SAS has acquired a certain preponderance over other social types regulated by law 19.550 . The central aspects that motivate or favor its application in commercial practice refer to the possibility of separating assets, the limitation of liability, the possibility to affect sole proprietorships, the separation of activities, and the simplification of registration and administrative procedures in its operation. Regarding the scope of the legality control carried out by the legal authority in the jurisdiction, it should be noted that it does not differ to a great extent from that which has been carried out for the other social types regulated by the LGS. The digital procedure to constitute these companies has not been implemented yet.

Regarding the exercise of the autonomy of the partners' will, and according to the professional practice, it is manifested mainly in the clauses related to the social object, the social capital and the disposition of the shares. In general, the model contract offered is adopted and adjustments are made to it in the referred clauses. Related to the risks of using the legal framework of the SAS for non-corporate purposes, it is necessary to recognize different jurisdictional realities. In any case, the accounting profession indicates its concern regarding this issue. By virtue of the above, and in order to mitigate the risks, to protect third parties, and to avoid potential corporate conflicts, it would be necessary to carry out legal and regulatory modifications in order to increase the powers of the jurisdictional control authorities, not only in the constitution but also in the operation of these companies.

Key words: simplified stock company; motivations for the constitution; legality control; autonomy of the will.

\section{A sociedade por ações simplificada (SAS) e seu desenvolvimento na jurisdição da província de La Pampa}

Resumo: O quadro jurídico oferecido pela Lei 27.349 de Apoio ao Capital Empresarial (LACE) constitui uma alternativa ideal para canalizar as pequenas e médias empresas na jurisdição da província de La Pampa. A figura da sociedade anônima simplificada (SAS) adquiriu certa preponderância sobre as demais modalidades sociais reguladas pela Lei Geral 19.550 das 
Sociedades Anônimas (LGS). Os aspectos centrais que motivam ou favorecem a sua aplicação na prática comercial referem-se à possibilidade de separação do património, à limitação da responsabilidade, à possibilidade de afectar as empresas individuais, à separação das actividades e à simplificação dos procedimentos de registo e administrativos no seu funcionamento.

Questão que atualmente está levantada no projeto de reforma da lei que regulamenta a SAS e que já conta com meia sanção do Senado da Nação. Entre as modificações propostas estão as seguintes: a inscrição dos empresários em Cadastro específico, a transferência do cadastro digital para a autoridade de controle para sua administração, controle e manutenção exclusivos, a obrigatoriedade de apresentação das demonstrações financeiras e a aplicação complementar de as disposições do LGS.

Palavras-chave: sociedade por ações simplificada (SAS); motivações para a constituição; controle da legalidade; autonomia da vontade.

\section{Introducción}

Esta investigación tiene por finalidad observar, describir y analizar las ventajas, los desafíos y riesgos que ha presentado y presenta en la actualidad la figura legal de la sociedad por acciones simplificada (SAS), creada en el marco de la Ley 27.349 de Apoyo al Capital Emprendedor (LACE). Este abordaje se realiza no solo desde una perspectiva teórica y doctrinaria sino también desde la práctica profesional de los contadores públicos en jurisdicción de la provincia de La Pampa.

Los debates académicos en torno de esta figura legal en general y de sus institutos en particular se han extendido hasta la actualidad. Estas discusiones doctrinarias señalan pormenorizadamente los beneficios y los riesgos que ha generado la implementación de la LACE desde su sanción en el año 2017. Es por ello que resulta oportuno y necesario llevar a cabo una revisión de estos aspectos controvertidos y una contribución desde la perspectiva de la práctica profesional en lo que hace a la constitución y funcionamiento de estas sociedades.

La pertinencia de este trabajo se manifiesta en la relevancia que ha adquirido esta figura legal, lo cual se expresa en las inscripciones societarias realizadas según el tipo. El Anuario Estadístico 2020 de la Provincia de La Pampa informa que en el año 2019 se inscribieron 86 sociedades por acciones simplificadas (SAS), 77 sociedades de responsabilidad limitada (SRL) y 10 sociedades anónimas (SA - SAPEM). Asimismo, su relevancia se manifiesta en el hecho de que, en la actualidad, se encuentra en tratamiento del Congreso de la Nación un proyecto de reforma de la ley que regula las SAS.

\section{Marco teórico: análisis doctrinario}

\subsection{Caracterización}

En Duprat (2017) se señala que la SAS constituye un nuevo tipo societario que cambia los paradigmas del derecho societario, con una impronta ya adelantada por el actual régimen de la sección IV del Capítulo I de la LGS en el que pre- 
domina la flexibilidad de las formas, lo que permite una mayor libertad de los socios para autorregularse. En efecto, el nuevo texto normativo referido a las sociedades residuales o libres de la Sección IV dio una importancia fundamental al principio de la autonomía de la voluntad y cambió fundamentalmente el régimen de la sociedad informal, o sea el de aquella que no acudió a instrumentarse como una sociedad típica (Perciavalle, 2017).

La SAS se expresa de esta manera como un nuevo tipo social que opera por fuera de la LGS. Se trata de una sociedad híbrida donde el capital se representa por acciones, pero con un carácter personalista muy fuerte (Vítolo, 2017). Es así que nos encontramos tanto con elementos propios del tipo como con componentes de la sociedad de responsabilidad limitada (SRL) y de la sociedad anónima (SA), con pretensiones de adaptarse, debido a su flexibilidad, a las necesidades del pequeño y mediano empresario (Duprat, 2017).

Con respecto a la responsabilidad que asumen los socios por las deudas sociales, en las SAS los socios garantizan solidaria e ilimitadamente a los terceros la integración de los aportes, coincidiendo en este punto con la responsabilidad que tienen los socios en la sociedad de responsabilidad limitada.

Un aspecto relevante a considerar refiere a la posibilidad de constituir SAS unipersonales con patrimonios de afectación diferenciados. El antecedente en el ordenamiento argentino se encuentra en la figura de la sociedad anónima unipersonal (SAU) regulada por la LGS. Asimismo, cabe resaltar que mientras que la SA tradicional y la SRL pueden ser constituidas con dos o más personas humanas o jurídicas, la LACE que regula a las SAS introduce la posibilidad de conformar sociedades también unipersonales. Es así que la legislación mercantil argentina ha ido mutando hacia el otorgamiento de la facultad de constituir emprendimientos unipersonales con patrimonios separados. Corresponde notar que tanto en las SRL como en las SA y en las SAS, las personas constituyentes pueden ser humanas o jurídicas. La única limitación que existe para el caso de las SAS, y que surge del primer artículo de la ley, es la prohibición para una SAS unipersonal de constituir o participar en otra SAS unipersonal.

En Favier Dubois y Spagnolo (2018) se reconocen ventajas sustantivas de la figura tales como: libertad estatutaria; admisión del objeto plural; transferencia de acciones que se rige exclusivamente por el estatuto sin necesidad de inscribirla; posibilidad de la indeterminación del plazo de los administradores; posibilidad de tener un solo administrador; reconocimiento de aportes irrevocables a cuenta de futuras emisiones sin capitalizarlos hasta los dos años; libertad para organizar la administración, gobierno y fiscalización; posibilidad de acudir al arbitraje; posibilidad de constituirse como una sociedad unipersonal; posibilidad de captar capitales mediante diversos tipos de acciones o por medio del crowdfunding o financiamiento masivo por internet. A ello se agregan ciertas facilidades formales tales como: el acto constitutivo puede realizarse por instrumento público o privado con firma certificada; el capital se divide en acciones y su 
monto puede ser de dos salarios mínimos vitales y móviles; aumentos de capital hasta el 50\% sin publicidad ni inscripción; inscripción en 24 horas (sujeto a las posibilidades de implementación de cada jurisdicción) si se opta por la utilización de estatutos modelo; no existencia de edicto para la convocatoria a las asambleas; autoconvocatoria para las reuniones de socios y administradores.

La SAS fue incorporada al ordenamiento jurídico argentino a partir de la sanción de la LACE en 2017. Esta ley se propuso fomentar el desarrollo de capital emprendedor en todas las provincias del país y, de esta manera, promover el desarrollo local de las distintas actividades productivas (Perciavalle, 2018). Asimismo, brinda cierta simplicidad y agilidad en la constitución, estructuración y desarrollo de la sociedad para ciertos nuevos emprendimientos (Molina Sandoval, 2017). Es así que se ha configurado para una parte de la doctrina como un instrumento muy importante para la pequeña y mediana empresa y para las empresas familiares, constituyendo un mecanismo revolucionario para todos los innovadores, los emprendedores y los pequeños y medianos empresarios (Vítolo, 2017).

En tal sentido, la LACE crea las herramientas necesarias para poner en marcha la ideas de quienes desean emprender y considera los problemas que generan la lentitud, las trabas y el elevado costo de los trámites que deben sortear los emprendedores para llevar a la práctica sus ideas innovadoras; para ello se crea la SAS, que se rige por normas mucho más flexibles a las que establece la LGS para las sociedades tipificadas en este ordenamiento legal (Perciavalle, 2018).

Asimismo, la finalidad de la ley no ha sido otra que favorecer a los emprendedores y jóvenes acostumbrados a actuar en el mundo digital con grandes ideas, pero sin recursos para armar una estructura y menos para financiar los proyectos. A esos fines, la ley facilita la actividad de los emprendedores y la constitución y financiación de nuevas empresas (Favier Dubois y Spagnolo, 2018).

En resumen, se manifiesta que las particulares características de este nuevo tipo societario tienen que ver con la extrema simplificación de los trámites de constitución, desarrollo, funcionamiento y cumplimiento de los deberes bancarios, tributarios y societarios (Suozzi, 2017). Su simplicidad, sumada a los beneficios que otorga la LACE, en cuanto a constitución, registración, publicidad, convocatoria, realización de reuniones, etc., son el marco jurídico más conveniente para las sociedades cerradas, aquellas que no apelan al ahorro público ni hacen oferta pública de sus acciones (Duprat, 2017).

\subsection{Incorporación de la figura en un plexo legal diferenciado de la LGS}

La primera cuestión debatible y que fuera señalada por la doctrina tuvo que ver con la incorporación de la figura en un plexo normativo por fuera de la LGS y su 
encuadre con otros institutos relativos al capital emprendedor. En Molina Sandoval (2017) se pone de manifiesto que la incorporación de las SAS en una "ley ómnibus" junto con otros institutos jurídicos no ha sido una técnica legislativa adecuada. De hecho, probablemente la mayor parte de las SAS que se inscriban no necesariamente se encuadrarán en los institutos regulados por la ley. Cualquier persona puede constituir una SAS, aunque no cumpla los requisitos para emprendedores o financiamiento colectivo. Hubiera sido aconsejable su regulación dentro de la LGS o, al menos, su regulación autónoma desvinculada de la aplicación de dichos institutos.

Sobre esta cuestión, en Nissen (2018) se expresa que la innecesaria inclusión de las SAS en una ley de apoyo al capital emprendedor ha sido solo una simple y burda excusa para poder contar con un disfraz societario en muy pocas horas, liberando a la misma de las formas y controles que la LGS establece para las sociedades legisladas en dicho ordenamiento en exclusivo beneficio de la comunidad, del tráfico mercantil, de los socios minoritarios y, fundamentalmente, en protección de terceros.

En conclusión, se manifiesta que no debería haberse sancionado en un cuerpo normativo independiente, con permanentes remisiones, sino mediante una adecuada modificación de la LGS e inclusión en ella del nuevo tipo societario creado, aprovechando esa oportunidad para darle simplicidad y coherencia al ordenamiento societario argentino, eliminando de la grilla de tipos a las sociedades caídas en desuso como las comanditas simple, las comanditas por acciones y las de capital e industria, como también las que con la incorporación de las SAS pasarán a formar parte de la historia como las sociedades colectivas (Abdala, 2018).

\subsection{Alcance del control de legalidad}

La segunda cuestión debatible refiere al alcance del control de legalidad y a las atribuciones de la autoridad de contralor. Primeramente, cabe notar que la LACE otorga la posibilidad de constituir SAS a través de dos formatos: el formato tradicional, que se realiza por instrumento público o instrumento privado con firma certificada por escribano, autoridad judicial, o autoridad bancaria, o un formato digital. En otros términos, la innovación que introduce la ley es la posibilidad de que la SAS sea constituida por medios digitales con firma digital, opción que no resulta posible para los otros tipos societarios.

La posibilidad que otorga la ley de utilizar estos dos caminos para la constitución de SAS trajo aparejado un arduo debate académico y doctrinario sobre el alcance del control de legalidad que debe ejercer la autoridad de contralor previa inscripción del contrato o estatuto social, en particular referido a la posibilidad de constituirlas en 24 horas a través del formato digital. Ello introdujo, asimismo, un cuestionamiento al propio sentido u objeto de los órganos de control jurisdiccionales. 
Para analizar el alcance del control de legalidad que realiza la autoridad de contralor es de destacar que la redacción del art. $6^{\circ}$ de la Ley 19.550 de Sociedades Comerciales anterior a la reforma del Código Civil y Comercial de la Nación (CCyC) expresaba que el juez debía comprobar el cumplimiento de todos los requisitos legales y fiscales, para luego disponer la toma de razón, previa publicación. Posteriormente, en virtud de la reforma, se suprimió del art. $6^{\circ}$ la referencia a tal comprobación de cumplimiento.

En efecto, la LACE dispone que la inscripción de la SAS en el Registro Público se realice dentro de las 24 horas contadas desde el día hábil siguiente al de la presentación de la documentación necesaria, siempre que se utilice el modelo tipo de instrumento constitutivo aprobado por cada jurisdicción. Desde la doctrina se advierte que esta alternativa podría conducir a una excesiva simplificación de las tareas de control y de conformación de los estatutos sociales (Duprat, 2017).

Para el caso en particular de las SAS, el control de legalidad previsto en el art. 38 de la LACE está a cargo de los funcionarios de la Inspección General de Justicia, siempre y cuando los otorgantes de la nueva SAS no hayan recurrido al estatuto tipo o estatuto modelo para constituir la misma, lo cual no constituía una opción en la Ciudad Autónoma de Buenos Aires, donde la IGJ, a través de la resolución 6/2017, solo autorizaba la constitución a través de un formulario de adhesión. En tal caso, el control de legalidad, traducido por lo general en un estudio minucioso de las cláusulas contractuales insertas en el contrato social o estatuto, quedaba reemplazado por la simple adhesión a un formulario continente de ciertas cláusulas usuales respecto de las cuales los socios solo deben llenar datos concretos o personales (Nissen, 2018).

\subsection{Aplicación del principio de la autonomía de la voluntad y flexibilidad en las formas}

El ejercicio de la autonomía de la libertad contractual para la conformación y posterior funcionamiento de las sociedades que se constituyen como entes jurídicos diferenciados viene precedido por un debate sobre el grado de regulación que un sistema legal societario debería contener. En tal sentido, la LGS estuvo signada históricamente por una impronta de corte imperativo, justificada en la creencia de que lo más conveniente era brindar a los empresarios una estructura societaria acabada con poco espacio para que las partes pudieran realizar modificaciones (Duprat, 2017).

Sin embargo, la modificación de ley 19.550, en oportunidad de la reforma del Código Civil y Comercial de la Nación por ley 26.994, incorporó al ordenamiento societario la figura de las sociedades residuales o libres en la Sección IV del Capítulo I. Ello constituyó un antecedente significativo dirigido a favorecer la libertad contractual y la aplicación del principio de la autonomía de la voluntad en el ámbito mercantil, en contraposición al señalado carácter imperativo original de la ley de sociedades. 
Asimismo, en Ramírez (2019) se señala la preponderancia de la autonomía de la voluntad, común en la mayoría de los ordenamientos modernos, tomada por el legislador al regular la SAS en la LACE, quien desde la nota de elevación al Congreso anticipa que concibe a la SAS como un régimen normativo que destaca y valora muy especialmente la libertad de creación de sociedades, su constitución y regulación contractual, sustentado ello en el principio de la autonomía de la voluntad y dejando librado a las partes la configuración de sus estipulaciones.

En el mismo sentido, se manifiesta que la incorporación de la SAS al menú de tipos societarios vino a traer una suerte de aire fresco al permitir una mayor injerencia del principio de la autonomía de la voluntad en el diseño de los estatutos sociales. En el caso de la SAS, el ámbito de libertad para la regulación del instrumento constitutivo se verifica, por ejemplo, en la posibilidad de pactar la forma de negociación o transferencia de las acciones, la prohibición de la transferencia de las acciones por tiempo limitado, la estructura orgánica de la sociedad, las funciones de cada administrador, la forma de convocatoria, de sesionar y tomar decisiones de los órganos sociales y la asignación de los derechos de voto a cada clase de acciones. La flexibilidad en las formas queda también expresada en la reducción de plazos de inscripción, la posibilidad de constitución por medios digitales, el objeto plural, el capital mínimo relativamente bajo, la no exigencia de la publicación e inscripción del aumento de capital inferior al 50\% y la admisión de libros digitales (Duprat, 2017).

En la SAS, la negociación y transferencia de acciones queda regulada en el instrumento constitutivo según se desprende del art. 48 de la LACE. Es válido el requerimiento de la aprobación de la reunión de socios para dicha transferencia. A diferencia de la SA y de la SRL, es posible pactar en el instrumento constitutivo la prohibición de la transferencia de las acciones o de alguna de sus clases, siempre que la vigencia de la restricción no exceda del plazo máximo de diez (10) años.

\subsubsection{Comparación de la SAS con la SA y la SRL}

En lo que respecta a la organización de la sociedad, en el art. 49 de la LACE se ve reflejada la autonomía de la voluntad que prima para las SAS al otorgarles la libertad a los socios de determinar la estructura orgánica de la sociedad y las normas que rijan el funcionamiento de los órganos sociales. No obstante, del mismo artículo surge que las mismas tendrán un órgano de gobierno, de administración y de fiscalización, coincidiendo así con lo estipulado para el resto de los tipos societarios.

El órgano de gobierno para las SAS y para las SRL es, en principio, la reunión de socios. Perciavalle (2018) señala que la reunión de socios no remite a una categoría orgánica determinada, pero tampoco la excluye. Se señala que la idea de reunir a los socios sobre una base deliberativa, en la cual se construye socialmente la decisión a través de la discusión de propuestas para luego someterse a votación, es una idea básica y propia de las sociedades personalistas. Pero lo 
cierto es que la LACE incluye también que las decisiones sociales se adopten mediante mecanismos consultivos. Para las SAS las reuniones sociales podrán celebrarse dentro o fuera de la sede social mientras que los socios utilicen medios que les permitan comunicarse entre ellos.

En la SA, el órgano de gobierno está a cargo de la asamblea. Según sea el tema a considerar, la misma será ordinaria o extraordinaria en los términos de los arts. 234 y 235 de la LGS. Tanto la asamblea ordinaria como la extraordinaria requieren un quórum para sesionar, siendo necesaria para la asamblea ordinaria en primera convocatoria la presencia de accionistas que representen la mayoría de las acciones con derecho a voto y en segunda convocatoria cualquiera sea el número de esas acciones presentes. En tanto para la asamblea extraordinaria se requiere en primera convocatoria la presencia de accionistas que representen el $60 \%$ de las acciones con derecho a voto, y en segunda convocatoria la presencia de accionistas que representen el $30 \%$ de las acciones con derecho a voto.

En lo que refiere a las mayorías, la LGS, en su art. 160, dispone para el caso de las SRL que serán los socios quienes establezcan en el contrato las reglas aplicables a las resoluciones que tengan por objeto su modificación. La mayoría debe representar como mínimo más de la mitad del capital social. En defecto de regulación contractual se requiere el voto de las tres cuartas partes del capital social. Si un solo socio representa el voto mayoritario, se necesitará, además, el voto de otro.

En las SA las resoluciones sociales, tanto en primera como en segunda convocatoria y en ambas asambleas, se toman por mayoría absoluta de los votos presentes que puedan emitirse en la respectiva decisión, salvo que el estatuto exija mayor número de votos. En tanto que, en el caso de las SAS, la ley no hace referencia específicamente a las mayorías, por lo tanto, se entiende que los socios tienen amplia autonomía para definir sus propias reglas; no obstante, en caso de silencio, se aplican supletoriamente las normas de la SRL y las disposiciones generales de la LGS.

La administración y representación en las SRL corresponde a uno o más gerentes, socios o no. Si la gerencia es plural, los socios pueden establecer en el contrato las funciones que le compete a cada gerente, o bien la administración conjunta o colegiada. En caso de silencio se entiende que pueden realizar actos de administración en forma indistinta. Por otro lado, la administración y representación en la SA estará a cargo de un directorio compuesto por una o más personas humanas, accionistas o no. El plazo máximo de duración de los cargos es de tres ejercicios. En las SA, del art. 299 de la LGS, se desprende que el directorio deberá ser integrado por lo menos con tres directores. En cuanto al órgano de administración, para las SAS el mismo está a cargo de una o más personas humanas, socios o no, designados por plazo determinado o indeterminado en el instrumento constitutivo o posteriormente. Asimismo, deberá designarse por lo menos un suplente en caso de que se prescinda del órgano de fiscalización. 
Por último, en cuanto a la fiscalización interna, para los tres tipos societarios el órgano es, en principio, optativo. Los socios pueden elegir entre una sindicatura o consejo de vigilancia, o en el caso de prescindir de ellos, se aplica el art. 55 LGS que establece el control individual de cada socio. Sin embargo, para aqueIlas SRL que queden incluidas en el art. 299, inciso segundo, resulta obligatorio contar con una sindicatura o consejo de vigilancia. Las SA que queden encuadradas en el art. 299 también en forma obligatoria deben contar con un órgano de fiscalización.

\subsection{Posiciones y debates respecto del alcance del objeto social en las SAS}

El art. 36 original de la LACE expresaba en su inciso cuarto que el instrumento de constitución debía contener la designación de su objeto, que podía ser plural, y que debía enunciar en forma clara y precisa las actividades principales que lo constituían, pudiendo guardar o no conexidad o relación entre ellas. Posteriormente, el art. 34 de la ley 27.444, publicada en junio de 2018, suprimió la necesidad de detallar las actividades que lo integran de manera clara y precisa.

En Ramírez (2018) se expresa que el objeto social en este caso adopta una naturaleza funcional y se compone por las categorías de actividades a través de cuyo desarrollo los socios satisfacen su ánimo de lucro. En tal sentido, se remarca que la SAS argentina quita relevancia al elemento objeto social, y por ende también a sus implicancias, dando una gran autonomía de la voluntad para que se establezca el objeto dentro del instrumento constitutivo en forma libre, amplia y plural. Sin perjuicio de ello, los socios siempre tienen la posibilidad de elegir un objeto social limitado o incluso único en caso de que consideren apropiado acotar la actuación de los administradores. Este aspecto, como veremos más adelante, se destaca en la práctica profesional en la constitución y funcionamiento de las sociedades.

Como puede observarse, tanto en la versión original como en la modificada, la regulación del objeto social para las SAS difiere de la prevista para las sociedades tipificadas en la LGS, en la cual se manifiesta que este debe ser preciso y determinado.

La conceptualización del objeto para la SAS, nuevamente, tanto en su versión original como en su versión modificada, que lo apartan de la caracterización "precisa y determinada" prevista en la LGS, ha suscitado numerosos debates y controversias doctrinarias, no solo desde lo conceptual sino también desde lo instrumental y desde la práctica profesional en la constitución y funcionamiento de este tipo social.

Se expresa en Ramírez (2018) que, con la incorporación de la SAS en el ordenamiento jurídico, el objeto social ha perdido normativamente la relevancia que históricamente se le había otorgado, dejando de ser un elemento esencial del 
contrato social. No parece aventurado suponer que pronto su inclusión será facultativa de los socios y al solo efecto de responsabilizar al administrador por actuar por fuera de ciertas actividades previamente delimitadas si así hubiera sido dispuesto.

En Perciavalle (2018), y en referencia al texto original del art. 34 de la LACE, se expresaba que no era convincente esta forma de abrir el objeto hacia una multiplicidad o pluralidad. Asimismo, se manifestaba que la redacción lucía al menos como contrapuesta entre la precisión y claridad de las actividades que se pretende desarrollar, por un lado, y la pluralidad por el otro.

Es así que no parece razonable que los objetos sociales, más allá del hecho de que las SAS formen parte de un plexo normativo distinto al de la LGS, tengan caracterizaciones y alcances diferentes, según sea el tipo social adoptado. Desde lo instrumental, tanto en la redacción original como en su versión modificada por la ley 27.444, el apartamiento de la caracterización prevista en la LGS generó un conjunto de incertidumbres innecesarias, toda vez que la regulación del instituto en la LGS ha sido bien ampliamente aceptado y tiene un desenvolvimiento fluido en la práctica constitutiva de los distintos tipos societarios. Como solución a la problemática del objeto, en Perciavalle (2018) se expresa que no se aboga por el conocido y limitado objeto preciso y determinado, sino que se inclina por la permisión del objeto plural, pero expresado inequívocamente y sin dejar de entrever en la normativa la posibilidad de que tal objeto plural se transforme en una vía que alecciona a los malintencionados a emplearlos subrepticiamente.

En Nissen (2018) se adopta una posición contraria a la laxitud del objeto social teniendo en consideración los efectos nocivos de la infracapitalización y atento a que si se admite un objeto plural e indiscriminado es absolutamente imposible garantizar a los terceros la función de garantía que el capital social ofrece, en especial tratándose de sociedades como las SAS, donde sus integrantes limitan su responsabilidad al aporte efectuado.

Finalmente, la posibilidad de establecer un objeto múltiple con un exiguo capital social y el limitado o inexistente control externo que le es otorgado a la autoridad de aplicación, y que varía de una jurisdicción a otra, hacen que esta figura deba ser aplicada con cautela si lo que se busca es un actuar responsable y transparente (Umansky, 2018).

\subsection{Capital mínimo para funcionar y su correspondencia con el objeto social}

El debate del capital social mínimo, la relación con el objeto y la infracapitalización sigue presente. El art. 40 de la LACE establece un parámetro que no solo tiene valor para las SAS, sino también para todo el plexo societario. La LGS no establece un capital mínimo para la sociedad de responsabilidad limitada ni 
para los otros tipos. En tal sentido, la SRL podría perfectamente tener un capital equivalente a dos veces el salario mínimo vital (Molina Sandoval, 2017).

Corresponde tener presente que tanto el capital de las SA como el de las SAS se representa en acciones, las cuales podrán ser nominativas no endosables o escriturales. Mientras que el capital de las SRL se divide en cuotas de un mismo valor. Continuando con el capital social, la SA como la SAS tienen un mínimo establecido por ley que cumplir, siendo para la SA de $\$ 100.000$ y para la SAS el importe equivalente a 2 veces el salario mínimo, vital y móvil. En tanto, remarcablemente, las SRL no tienen capital mínimo estipulado.

En lo que se refiere a la suscripción e integración del capital, si bien el art. 41 de la LACE establece que el mismo deberá hacerse en las condiciones, proporciones y plazos previstos en el contrato constitutivo, la integración en dinero en efectivo no podrá ser inferior al $25 \%$ y la integración del saldo no podrá superar el plazo máximo de dos años, mientras que los aportes en especie deben integrarse en un $100 \%$ al momento de la suscripción.

Respecto a la constitución y capitalización de aportes irrevocables a cuenta de futuros aumentos de capital, la doctrina no ha sido pacífica. Por una parte, se manifiesta que las SAS tienen un sistema muy permisivo para los aportes irrevocables a cuenta de los futuros aumentos de capital, y esto es muy práctico porque en el régimen general, en casi todas las jurisdicciones, las autoridades de contralor han dispuesto que los aportes irrevocables a cuenta de los futuros aumentos de capital no puedan permanecer como tales en esa cuenta de patrimonio neto por más de 180 días. En las SAS podemos tenerlos dentro del patrimonio neto hasta por 24 meses, lo que otorga un margen de maniobra enorme para mantener el equilibrio patrimonial mientras se desarrolla el emprendimiento (Vitolo, 2017).

Por la otra, en Nissen (2018) se expresa que la LACE no se ha olvidado de los aportes irrevocables ofreciendo la extensión del plazo de su capitalización a 24 meses contados desde su aceptación por el órgano de administración, lo cual resulta un plazo sumamente excesivo, pues conspira contra la propia naturaleza del instituto y permite todo tipo de manipulación del patrimonio social por parte del grupo de control según la apariencia de solvencia que quiera exhibir la sociedad en un momento determinado.

\subsection{Riesgos de la figura: persecución de fines extrasocietarios}

Parte de la doctrina señala los riesgos que implica la instrumentación de esta figura legal. En efecto, la LACE autoriza la creación de este nuevo tipo social en un plazo de 24 horas, sin control de legalidad ni control de funcionamiento, sin las previsiones expuestas en la LGS en torno a la necesidad del socio único de integrar totalmente el capital social y sin necesidad de contar con órgano 
de fiscalización interno. Tampoco resulta obligatorio exhibir y acompañar los estados contables a la Inspección General de Justicia (IGJ) como lo exige el art. 67 LGS (Nissen, 2018).

Es por ello que estas sociedades podrían ser usadas por sujetos inescrupulosos como instrumentos idóneos para violar la ley y perjudicar a terceros. En efecto, la posibilidad de fijar un objeto múltiple con un exiguo capital social y el limitado o inexistente control externo que le es otorgado a la autoridad de aplicación, y que varía de una jurisdicción a otra, hacen que esta figura deba ser aplicada con cautela (Umansky, 2019).

\section{Metodología aplicada: análisis de contenido cualitativo}

El relevamiento de los datos cualitativos se materializó a través de la realización de entrevistas semiestructuradas dirigidas en primer lugar al Director General de la Dirección General de Superintendencia de Personas Jurídicas y Registro Público de Comercio (DGSPJyRPC) de la jurisdicción de la provincia de La Pampa; y luego a cinco contadores públicos responsables de estudios profesionales dedicados a la constitución y asesoramiento societario, en particular, con experiencia en constitución y funcionamiento de SAS. Dichas entrevistas tuvieron una duración de 45 minutos cada una aproximadamente y se realizaron durante los meses de junio y julio de 2021.

Las entrevistas fueron grabadas, transcriptas y analizadas mediante la técnica de análisis de contenido cualitativo. Esta técnica de análisis consiste en la interpretación que realiza el investigador de datos de contenido textuales a través de un proceso sistemático de codificación e identificación de patrones o temas (Hsieh y Shannon, 2005). El objetivo del análisis de contenido cualitativo es lograr una descripción del fenómeno y el resultado del análisis se traduce en conceptos o categorías que lo describen. El propósito de estos conceptos o categorías es la construcción de un modelo, sistema o mapa conceptual (Elo y Kyngas, 2007).

En la metodología de análisis de contenido, el investigador realiza un proceso de codificación del texto para luego clasificarlo en subcategorías, establecer relaciones entre las mismas y construir posteriormente categorías conceptuales generales en un proceso de abstracción creciente. Categorizar significa agrupar códigos similares o comparables para la construcción de patrones y para la realización de análisis posteriores. Interrelacionar consiste en proponer conexiones entre los elementos constitutivos del análisis de datos (Saldaña, 2014). Se trata, entonces, de explorar cómo las categorías y los patrones emergentes se interrelacionan.

Como resultado final del proceso investigativo, el enfoque de análisis cualitativo de datos propone la construcción de mapas o cartas conceptuales a partir de los códigos, subcategorías y categorías generales y principales, donde se logra 
el mayor grado de abstracción y construcción teórica (Cho y Lee, 2014; Elo y Kyngas, 2007). En tal sentido, podrá apreciarse más adelante como resultado de esta investigación la carta conceptual correspondiente.

\section{Análisis y resultados obtenidos a partir de la aplicación de la metodología propuesta ${ }^{(1)}$}

\subsection{Categorías y subcategorías}

\subsubsection{Aplicación y adopción de la SAS por pequeños y medianos emprendimientos locales y regionales}

De acuerdo a lo manifestado en las entrevistas, la figura de la SAS resulta ser un instrumento que facilita la constitución de emprendimientos locales y regionales de distinta índole. En general, este tipo societario es aplicado a pequeños o medianos emprendimientos personales o eventualmente familiares. Surge como una alternativa más ajustada y responde a las necesidades de este segmento de pequeñas empresas:

En La Pampa, lo que implicó (...) es una figura nueva para muchos emprendedores con un costo menor de mantenimiento; la figura no es mala, como todo, depende para qué se use. (Director General [DG])

Una persona que va a invertir dice, ¿̇de qué manera? (...) asociándose a alguien, porque por ahí solo no lo puedo encarar. Y si me asocio a alguien, ¿de qué manera lo implemento, (...) impositivamente? Entonces, este fue un caso particular en el que cada uno tenía su actividad y con el ahorro que tenían querían encarar una inversión; esta fue la herramienta. (Entrevistado 3 [E3])

Ahora tengo tres emprendimientos, uno de ellos es una granja, otro es una fábrica láctea, y el tercero tiene un criadero de pollos; ellos quieren vender su producción sin intermediarios en forma conjunta; entonces, encontramos esta figura para iniciar la comercialización; son tres personas distintas y crean una sociedad. [E3]

En el perfil que manejamos: en general son empresas pequeñas de La Pampa, muchas familiares, y unipersonales (...) Era como crear todo un aparato demasiado grande y ahora no, para mí desde ese sentido esto es mucho mejor. (Entrevistado 1 [E1])

Pequeños clientes, que son la mayoría de los que tenemos en la provincia. Se ha adaptado a la realidad del pequeño emprendimiento. Acá son muy pequeñas (...) son solo uno o dos socios, son los mismos que administran (...) Es la familia en general; socios que sean terceros, es muy poco común, es la realidad de La Pampa. (Entrevistado 2 [E2])

En general, son pequeños emprendimientos (...) me parece que sin esta herramienta mucha inversión quedaría en la nada, por no tener la posibilidad de encararlo de algu-

\footnotetext{
(1) Los comentarios de los entrevistados que se enuncian son a título ilustrativo y responden a las codificaciones, subcategorías y categorías analíticas construidas. A lo largo de la investigación se manifestaron evidencias empíricas y comentarios adicionales en igual sentido y con la misma significación. Para evitar repeticiones, se han incluido solo algunos de dichos comentarios. A partir de las subcategorías y categorías analíticas se construyó el mapa conceptual que puede apreciarse al final de la sección.
} 
na manera (...) si saben que es rápida (...) vienen y dicen yo quiero encarar tal o cual negocio. [E3]

Las armamos para cositas chiquitas, emprendimientos muy chicos; si alguien quiere poner una fábrica de ladrillos no voy a armar una SAS, por ahí otra figura, una SRL. (Entrevistado $5[\mathrm{E} 5]$ )

\subsubsection{Preponderancia de la figura por sobre otros tipos sociales}

El marco legal de la SAS para la constitución de emprendimientos de naturaleza societaria ha adquirido preeminencia sobre los otros tipos societarios tales como la SRL y la SA, según se manifiesta en los comentarios realizados por los entrevistados. Esta preponderancia se corresponde con el número de SAS constituidas, por ejemplo, en 2019, por sobre los otros tipos societarios, tal lo expresado en la introducción de este trabajo:

No hicimos más SRL (...) desde que salió la ley arrancamos y después hicimos todas SAS. Respecto de la figura de SRL (...) por ahí tenés un cliente tradicional, o que venga ya formado con la idea de la sociedad anónima. [E1]

Las últimas sociedades que se han constituido, desde que está vigente esta figura, han sido todas implementadas como sociedades por acciones simplificadas (SAS) (...) Desde que se implementó esta figura de las SAS no constituimos más SRL. [E2]

Desde que salieron, acá en el estudio constituimos más SAS que otros tipos societarios, casi te diría que un $80 \%$ fue SAS, un $15 \%$ SRL y el resto SA; en el caso de las SAS siempre orientadas a los pequeños emprendedores. [E5]

\subsubsection{Adopción y difusión de la SAS en la jurisdicción por parte de la profesión contable}

La figura y el marco legal de las SAS se han adoptado paulatinamente en el ámbito de la jurisdicción de la provincia de La Pampa. La profesión contable ha contribuido a su difusión desde el asesoramiento profesional, cuestión que se manifiesta a continuación:

Entonces, no sé si nos hemos enamorado de las SAS, pero las difundimos mucho (...) en general cuando hablamos con colegas que no las defienden tanto porque piensan que van a desaparecer; pero mientras esté la ley y esté la herramienta, nosotros vamos a aprovechar sus beneficios. [E1]

En general lo han visto en los diarios, hay algunos que ya la conocen; te diría mitad y mitad. [E2]

Después, lo que se ha generado, acá en La Pampa todo es muy chico (...) ya está bastante incorporado en la sociedad la existencia de la sociedad por acciones simplificada (...) una de las que voy a constituir ahora (...) la sugirieron ellos, sabían que existía (...) y yo también la he difundido, ahora es más común que antes. [E3]

Muchas veces los clientes no te entienden; en general piensan que las sociedades anónimas son empresas gigantes y que las SRL son empresas chiquitas; entonces las diferencias no terminan de saberlas (...) y muchas veces pasa eso (...) empresas que comenzaron a tomar volumen (...) explicarles: mirá, tenés esto para separar patrimonios, tenés beneficios impositivos. Sirve para ordenarlos; pero eso es más una educación y seguimiento que hacemos nosotros. [E4] 
Al principio la incentivamos nosotros, ahora ya están viniendo porque escuchan a tal o cual, se informan en los diarios (...) Les interesa saber, les explicás, la verdad que las SAS están mucho en los medios, la gente está informada, no sé si bien informada, pero sabe lo que es una SAS, también sabe todas las críticas que hoy por hoy se les están haciendo. [E5]

\subsubsection{Aspectos y motivaciones que favorecen su utilización en la práctica mercantil}

Los aspectos y motivaciones que favorecen la utilización de la figura en la práctica mercantil se relacionan con la posibilidad de crear patrimonios de afectación diferenciados. Esta separación patrimonial permite realizar actividades que pueden desarrollarse autónomamente. La limitación de la responsabilidad a la integración del capital comprometido al momento de la constitución favorece nuevas iniciativas y actividades empresariales. También se destaca cómo esta figura legal permite ordenar administrativa y contablemente la actividad emprendedora. Viene, asimismo, a subsanar la obligatoriedad de asociarse con otros sujetos para poder constituir sociedades, dado que se permite la constitución de entes jurídicos unipersonales. La figura de la sociedad anónima unipersonal (SAU) no resultaba aplicable dado que estaba destinada a la gran empresa. En cierta medida, el marco legal de la SAS también simplifica desde la práctica empresarial los trámites administrativos formales, cuestión que por otro lado reduce el grado de intervención de la autoridad de contralor. El marco legal de la SAS también es utilizado en la práctica profesional como estrategia impositiva en determinadas circunstancias tales como la separación de actividades en empresas unipersonales o en situaciones en las que los emprendedores deciden asociarse.

- Separación patrimonial y limitación de la responsabilidad:

La finalidad para la que las constituimos es para separar patrimonios, algunos que ya venían trabajando como personas humanas con mucha antigüedad (...); hay muchas unipersonales con ese fin (...) Entonces, encontramos esta figura, la SAS, que les permitía tener ese patrimonio separado, protegido. [E1]

Lo que buscan básicamente los clientes son los beneficios de la separación patrimonial y la limitación de la responsabilidad. [E2]

Por un lado tengo el estudio y por el otro un negocio propio, una actividad vinculada a lo agropecuario, entonces se me ocurrió utilizar la SAS (...) en mi caso, particularmente, lo hice para limitar un poco la responsabilidad, sumado a que la podés hacer unipersonal (...) a partir de eso, lo empecé a comentar a algunos clientes. [E3]

Buscan armar la sociedad para proteger su patrimonio particular; ése es el objetivo primario. [E5]

- Motivaciones de la separación patrimonial:

Un cliente que quiere separar un negocio para crear un valor llave, que sabe que después lo va a terminar vendiendo (...) entonces lo vende con todo el paquete (...) con la trasmisión de las acciones vendió todo el negocio funcionando. Eso también, tenemos un cliente que tiene dos restaurantes (...) y uno lo tiene como persona física... porque se lo va a quedar; y el otro ya lo hicimos con la SAS y cuando venda ya vende el paquete (...) la sociedad ya tiene el objeto que es de gastronomía. [E1] 
A la hora de sacar un préstamo se plantean si lo saca la sociedad o si lo sacan ellos (...) tratamos de fortalecer a la sociedad para que tenga antecedentes bancarios; realmente la separación de patrimonios, para nosotros, funciona. (Entrevistado 4 [E4]

\section{- Ordenamiento del emprendimiento:}

También nos ha pasado que al hacerlas sociedad logramos que se ordenen mucho los clientes porque empiezan a verlo como una persona separada, ya lleva balances; y siempre que los ordenás crecen (...) pese a que estamos en pandemia hay clientes que han crecido muchísimo (...) yo se lo atribuyo mucho a eso (...) a que la figura los ha ordenado. [E4]

Es como que le tienen otro respeto; está bueno, si bien dejan de ser ellos y es otra persona la sociedad (...) se lo han tomado como algo más formal, más estructurado, entonces (...) es más fácil explicarles por ejemplo (...) si gastamos más de lo que ingresa algo está pasando; es más fácil de mostrar, los ordenamos a que tengan un retiro y que lo cumplan. [E4]

Los ordena, nosotros tenemos que llevar una contabilidad; entonces los ordenamos también a ellos; a diferencia de cuando es una empresa unipersonal (...) tienen ordenados los proveedores, los clientes, siempre terminan con mayores rentabilidades, termina siendo el resultado de eso. [E5]

\section{- Viabilidad de emprendimientos o patrimonios de afectación unipersonales:}

La persona que tenía un negocio o un patrimonio grande (...) tenía que generar una SRL o una SA; y como consecuencia estaba obligada a asociarse con alguien (...) entonces siempre estaba pendiente esa cuestión. [E1]

Otra ventaja es que puede ser de un solo socio; para las empresas unipersonales, que por ahí acá es bastante común (...) a veces había que buscar otro socio con el $1 \%$ o el $5 \%$, pero en definitiva era como una sociedad unipersonal. [E2]

Ahora es más real. La gente puede elegir por sí misma la figura (...) La otra salida era incorporar a otro socio (...) y terminás por incorporar a gente que nada que ver. [E1]

\section{- Simplificación de trámites administrativos formales:}

Es más práctico, por ejemplo, en un cambio de gerentes, hacés un acta y ya está; no tenés que inscribirlo (...) el cambio de domicilio, cuando está fuera del estatuto y no tenés que informar a personas jurídicas (...) en realidad, cuanto la constituís sí, pero después no, salvo que cambies de jurisdicción. [E1]

Lo hacés por instrumento privado, hacés un acta y la transmisión de acciones (...) no se informa a personas jurídicas (...) Tenés el libro de registro de accionistas y acciones; lo dejás asentado ahí. [E1]

En la transmisión de las acciones, en el caso de las SAS, no habría que inscribirlas en personas jurídicas, porque es similar a la anónima, pero en las SRL sí (...) así que también eso sería una ventaja para las SAS. [E2]

El control anual de presentación de asambleas en el registro de personas jurídicas para las sociedades anónimas, que no es nada complejo, pero es un trámite más (...) con el atosigamiento de la burocracia (...) con las SAS es un trámite menos. Acá [con las SAS] se puede designar un administrador que no tiene plazo de vencimiento de mandato; en la anónima es hasta tres años como máximo. [E2]

Si vos creás una SRL, con mucho viento a favor en un mes y medio o dos la sacás; y la SAS es mucho más rápido, una semana. La mayoría, cuando quieren empezar una 
sociedad, es porque ya tienen armado el proyecto (...) solamente les falta la forma jurídica para arrancar. [E5]

- Forma de separación de actividades:

También para separar actividades (...) para que puedan mantener el Monotributo para una actividad como un servicio, y constituir una SAS para una actividad comercial o para venta de bienes, eso también. [E4]

- Aplicable a emprendedores que deciden asociarse:

"Después constituí dos más; en el primer caso, eran dos transportistas. El monotributo viene quedando atrás cada vez más; facturaban los dos como monotributistas; podrían haber seguido uno como monotributista y el otro como responsable inscripto (...) les sugerimos lo de la sociedad por acciones simplificada (...) y se decidieron por la sociedad. [E3]

\subsubsection{Constitución de la SAS}

\subsubsection{Alcance del control de legalidad en la jurisdicción}

En lo que hace a la constitución de las SAS, la autoridad de contralor de la jurisdicción, que es la DGSPJyRPC, participa del control de constitución de estas sociedades, independientemente de que los emprendedores utilicen el contrato modelo o no. Surge de las entrevistas realizadas que las observaciones que realiza la autoridad de contralor lógicamente son menores cuando se utiliza el contrato modelo diseñado por esta autoridad. Cuando los socios no siguen el contrato modelo y se realizan modificaciones a las cláusulas contractuales, que normalmente tienen que ver con el objeto, con el capital social y con la cesión de las participaciones accionarias, la autoridad de contralor realiza las observaciones que considera pertinentes para que sean modificadas.

En nuestra jurisdicción sí o sí interviene Personas Jurídicas (...) siempre existe un control de legalidad (...) si ellos ven algo que no está bien, no solamente con esta sociedad, te llaman (...) el control de legalidad no es diferente al que realizan en los otros tipos sociales, es exactamente igual. [E5]

Si es el contrato modelo, miran el capital, las personas que lo integran, los datos necesarios; y después, en general, no hay observaciones. Si le haces modificaciones sí, de hecho, me han llamado del registro, he tenido que ir a hablar, les explico el porqué de las modificaciones; no deja de ser rápido; pero yo lo presento, y a los dos o tres días me están llamando para que les explique esas modificaciones, por qué las hice. [E5]

Creo que fue positivo; en CABA está cuestionada (...) estaba fuera del ámbito de la IGJ; de ahí creo que vino el cuestionamiento (...) acá no ocurre eso, porque está todo en Personas Jurídicas. [E2]

\subsubsection{Digitalización}

En la jurisdicción aún no se ha implementado la digitalización del trámite en 24 horas ni la firma digital, tal como lo autoriza la ley, con lo cual no se han manifestado problemáticas vinculadas a esta cuestión, tal como había sido señalado 
en su oportunidad por la doctrina societaria relativas a la ausencia o limitación en el control de legalidad. En lo que hace al trámite digital, se advierten distintas realidades jurisdiccionales relativas a la disponibilidad de recursos y a la factibilidad de implementar el trámite digital en el corto plazo:

Si hablamos de la digitalización te puedo decir que la condición nuestra (...) como en 2017, 2018, y aún hoy, son las SAS soporte papel (...) Esto se lanzó de esta forma; diciendo que en 24 horas vos tenías una sociedad constituida y lista para operar (...) acá con suerte quizás en una semana y algunos días es posible que la tengas. $[D G]$

Y si a eso le sumás que se lo trató de vender con todo el tema de la digitalización (...) se entró a chocar con el resto de todas las jurisdicciones que no estábamos a la altura de la ciudad de Buenos Aires, IGJ, AFIP (...) Es distinta la infraestructura que tienen. [DG]

Pero no puedo comparar Capital Federal, que donde sea tienen wifi, con otras jurisdicciones; acá nosotros mismos (...) ¿Yo la voy a constituir en un día? No, no puedo (...) la misma plataforma, el CUIT, hacés interactuar muchas cuestiones. [DG]

La SAS nace más desde el dinamismo de lo digital y acá hacer una SRL te lleva un mes y medio; y con las SAS (...) no son las 24-48 horas que te habla la ley (...) a veces lo planeás bien desde la concepción de la sociedad, pero después... [E1]

Acá la digitalización y el trámite en 24 horas no se materializó, ni se va a materializar tampoco+. [E5]

\subsubsection{Ejercicio de la autonomía de la voluntad}

En lo que hace al ejercicio de la autonomía de la voluntad para conformar el instrumento de constitución, tanto los emprendedores interesados como los profesionales que los asesoran utilizan en general el contrato modelo ofrecido por la autoridad de contralor, al cual se realizan ciertas modificaciones o adecuaciones, particularmente vinculadas a las cláusulas relativas al objeto, al capital social y a la disposición de la participación accionaria. En el devenir mercantil y en la práctica empresarial, el ejercicio de la autonomía de la voluntad queda circunscripto a estos aspectos. En lo referente, por ejemplo, a la organización societaria, se utilizan las cláusulas usuales del contrato modelo. Se indica, asimismo, que la utilización del contrato modelo restringe en la práctica la pregonada autonomía.

Respecto del objeto social, la profesión contable que asesora en constitución de sociedades recepta la pluralidad de actividades y sugiere a sus clientes cierto grado de priorización o correspondencia entre las mismas. Respecto del capital social, se adopta un monto superior al mínimo legal sugerido atento a la naturaleza del objeto o de la actividad que se pretende desarrollar, y a la viabilidad financiera del emprendimiento. No se observan desde la práctica profesional ventajas explícitas vinculadas a la utilización del capital mínimo legal, dado que ello conlleva posteriormente a capitalizar los potenciales aportes irrevocables que se realicen. Al contrario, se evidencian ciertos beneficios de adoptar un capital superior al momento de la constitución. 
- Utilización del contrato modelo de la autoridad de contralor con ciertas adecuaciones:

Hemos tomado el contrato modelo porque está bastante completo (...) lo cierto es que son negocios chicos que buscan un marco jurídico para limitar la responsabilidad (...) pero que no va más allá de la formalidad y no se ponen a pensar (...) porque para hacer uso de esa autonomía de la voluntad habría que pensar más a futuro (...) en general, para este tipo de clientes (...) viene a buscar rápido una sociedad para empezar a operar. [E2]

Nosotros utilizamos el contrato modelo que es bastante amplio; porque yo veo en ciertos casos [que] eligieron esa actividad porque se les ocurrió, por una oportunidad de negocios (...) pero también pueden ir para otro lado (...) entonces, no voy a limitar el objeto social; por eso uso ese contrato modelo que es bastante amplio. Se les puede ocurrir tener otra actividad relacionada o no necesariamente con la original (...) Lo más práctico que me ha resultado es usar el contrato modelo. [E3]

Generalmente usamos el contrato modelo de personas jurídicas; tienen un instructivo, (...) las adecuaciones las usamos (...) siempre hacemos una reunión y les indicamos cuáles son las incumbencias que tienen; y también mucho la de la limitación a la transmisión; para que haya acuerdo; esa en general la modificamos. [E4]

En algunos casos usamos el contrato modelo y en otros lo adaptamos, sobre todo la parte del objeto social. En una sociedad de profesionales le tuvimos que adaptar el objeto; si no es el contrato modelo. [E5]

- Restricciones a la autonomía de la voluntad:

Usando el contrato modelo, generalmente. Bueno, esa es otra de las discusiones que tuvimos en su momento, porque te hablan de la autonomía de la voluntad (...) todo muy lindo, pero la autonomía de la voluntad funciona si les permitís armar su propio contrato; si para que salga en 24 horas me tengo que subsumir a esto [modelo contractual preestablecido] estoy en lo mismo que si fuera un contrato de seguro con cláusulas predispuestas; ¿Dónde queda la autonomía de la voluntad ahí, en lo que yo quiero hacer? Estas eran las críticas que hacíamos en 2017. [DG]

\section{- Limitación o extensión del objeto social en la práctica profesional:}

"En general, lo que hacemos es hablar con el cliente y ver; porque si no (...) ¿todo? (...) ¿arrendamiento rural? (...) si no tenés previsto comprar un campo (...) no pongamos arrendamiento rural (...) ¿objeto financiero? Si no vas a tener una actividad financiera (...) tratamos de que haya cierta lógica. [E1]

El contrato modelo ofrece un objeto totalmente amplio; lo que hacemos nosotros es ordenar los ítems arrancando por lo que sería la actividad principal, por una cuestión de orden digamos, pero lo dejamos igual amplio porque en el devenir del negocio es probable que aparezcan otras actividades, cosas que estén medianamente relacionadas obviamente. [E2]

Vamos a suponer, se quieren asociar médicos, por darte un ejemplo, muchas veces los colegios profesionales tienen restricciones respecto del objeto de la profesión, entonces yo ahí tengo que adecuar el objeto (...) o por ejemplo en determinadas actividades (...) el objeto tiene que estar perfectamente identificado (...) son cuestiones muy puntuales (...) lo dejas amplio, pero haces un párrafo aparte dejando indicada esa actividad. [E5]

- Monto del capital social: su relación con el objeto:

Es muy difícil, porque lo hemos discutido también, pero quién tiene la capacidad para saber si el capital va a dar o no, o te va a servir para el cumplimiento del objeto. Porque 
si me decís que una SRL tiene cien mil pesos y se va a dedicar a hacer edificios; hoy con cien mil pesos no haces ni diez metros de vereda. [DG]

El capital mínimo (...) siempre, es más, no les recomendamos nunca el mínimo fijado por la ley (...) Entonces, nosotros les explicamos, en función de qué expectativas y de qué visión tienen, siempre les recomendamos un mínimo acorde. [E1]

Que el capital sea acorde a la actividad; o sea, si voy a hacer hotelería, con $\$ 12.000$ no compras ni una almohada (...) entonces, no te sirve de nada (...) Es un costo que tenés que asumir al inicio (...) Cuando sos unipersonal, el costo de proteger tu patrimonio personal, tu casa, todo lo tuyo personal (...) por ahí está en nosotros hacerles entender esa parte. [E1]

Los casos que hemos tenido han sido realmente muy pequeños. Para el tipo de emprendimiento que se hace acá, esa discusión de la relación entre el capital y el objeto no es tan relevante; por ahí eso es una cuestión más de otro ámbito; acá las últimas dos que hemos hecho pusimos $\$ 300.000$ por decirte, que es bastante más que el mínimo, pero (...) es difícil saber cuánto es el importe realmente; por ahí para eso personas jurídicas tendría que exigir un análisis tipo proyecto de inversión, de viabilidad en su caso. [E2]

No las hago con capital bajo, es más un criterio contable. Suponé que creamos una SAS para comprar una camioneta para hacer fletes, y pones $\$ 100.000$ de capital (...) entonces no; si vas a comprar eso, como mínimo tenés que tener ese capital. Si no después tenés que presentar trámites, aumentos de capital (...) lo hacemos bien de una. [E5]

- Beneficios de un capital superior al mínimo:

Por ejemplo, por la calificación crediticia de los bancos; sabiendo el costo que implica el impuesto de sellos, pero después ganás en la calificación crediticia, le abrimos la cuenta bancaria, entonces, ya entran al banco con una calificación crediticia. [E4]

\subsubsection{Riesgos de la aplicación de la figura legal: persecución de fines extrasocietarios}

El riesgo de una inadecuada utilización de la figura resultaría ser mayor en jurisdicciones tales como la Ciudad Autónoma de Buenos Aires. De todos modos, la profesión contable señala su preocupación respecto de la posible utilización de esta figura legal con fines extrasocietarios:

Tiene que ver con el uso que se le da. Si ponen solo $\$ 50.000$ de capital, pueden hacer un lío, porque la responsabilidad es solo de $\$ 50.000$ pesos. Pero igualmente el mismo lío lo pueden hacer con una SRL. Pueden usar la misma mala intención en cualquier figura, en una SRL o en una SA; no responde a la figura en sí. [E1]

El problema más grande que tiene la SAS es que desprotege al acreedor; puede llevar a una sociedad fantasma (...) yo creo que se puede prestar mucho a eso (...) es una crítica que hace Nissen, pero también lo pueden hacer con otras sociedades. [E5]

Podés desconfiar un poco más en Capital Federal, por ahí puede pasar que no conocés a los clientes, pero acá es como que no hay chances de que se pueda crear una sociedad con un objeto que realmente no tenía. [E1]

Acá en nuestro medio, ninguna de las cuestiones se plantean a nivel nacional. Primero porque el organismo de control es el mismo. Segundo, que acá no hay gente que se dedique a cosas raras digamos (...) Acá eso no existe. [E2] 
No, acá no, acá nos conocemos todos, la mayoría conocen a los inspectores de AFIP, nos encontramos en un restaurant, en el club; acá esas problemáticas no se dan (...) en Capital Federal calculo que sí. [E5]

\subsubsection{Ausencia de conflictos societarios en la jurisdicción desde la sanción de la ley}

Según se pudo constatar, en la práctica profesional no se han advertido conflictos societarios ligados al funcionamiento de la figura; sin embargo, es importante destacar que han transcurrido pocos años desde la sanción de la ley de su creación:

Son muy recientes, con lo cual te diría que no han surgido conflictos, pero sí tengo la precaución de decirle al cliente lo que conlleva tener una sociedad si lo comparamos a actuar como persona física; es muy distinto, no solo en el manejo sino también en el costo en general, porque la gente está acostumbrada (...) saca el dinero (...) y no es así en una sociedad. [E3]

No, no, conflictos societarios ninguno, y conflicto hacia terceros tampoco. Son demasiado jóvenes como para que haya algún tipo de problema, como para que una sociedad que haya entrado en concurso o quiebra. [E5]

\subsubsection{Mapa conceptual sobre el desenvolvimiento de la SAS}

Puede observarse a continuación el mapa conceptual derivado del trabajo realizado y que se expresa como resultado de esta investigación.

Gráfico 1. Mapa conceptual del desenvolvimiento de la SAS en la jurisdicción

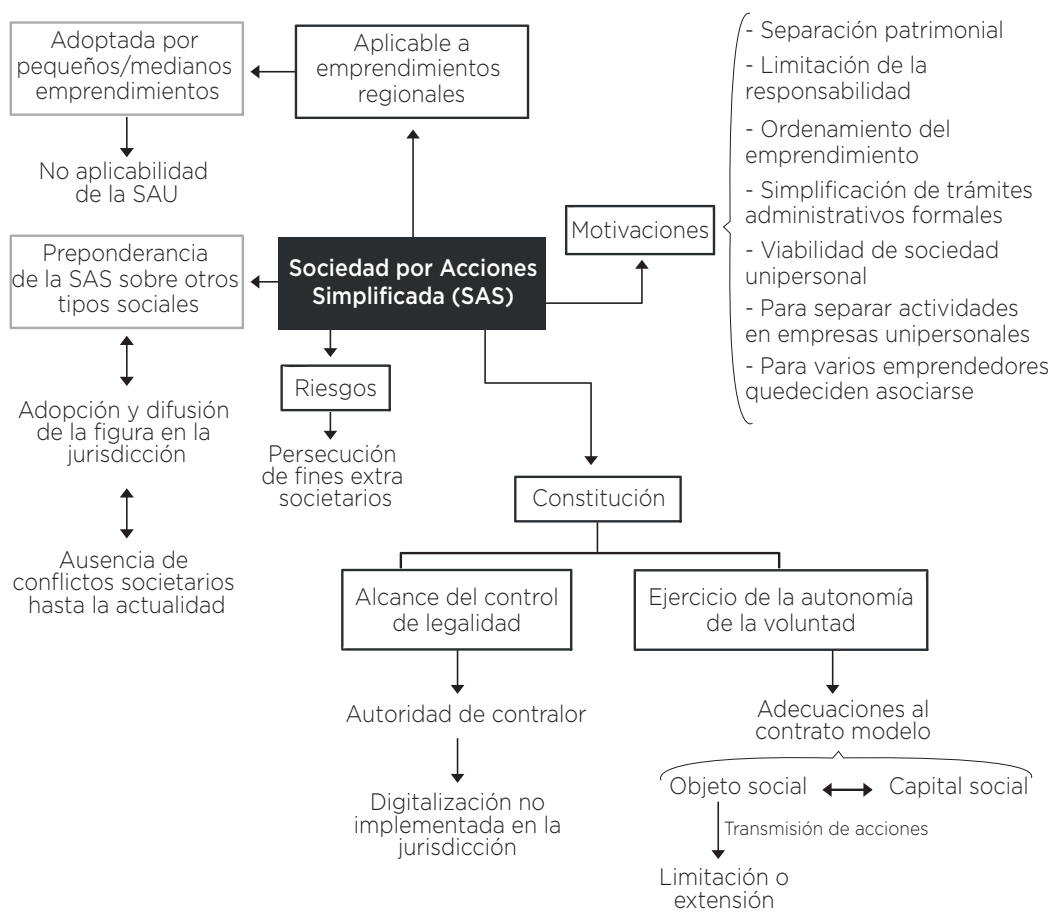




\section{Conclusiones y discusión}

El marco legal que ofrece la LACE constituye una alternativa idónea para canalizar pequeños y medianos emprendimientos en la jurisdicción de la provincia de La Pampa. La figura de la SAS ha adquirido cierta preponderancia por encima de otros tipos sociales regulados por la LGS, lo cual se manifiesta en su difusión y en su adopción por parte de los emprendedores regionales.

Los aspectos centrales que motivan o favorecen su aplicación en la práctica mercantil tienen que ver con la posibilidad de separar patrimonios, la limitación de la responsabilidad, la posibilidad de afectar patrimonios unipersonales, la separación de actividades y la simplificación de los trámites registrales y administrativos en su funcionamiento. Cabe tener presente que estos aspectos hacen que la figura deba aplicarse con cautela y prudencia, como lo ha manifestado parte de la doctrina.

En lo que refiere al alcance del control de legalidad que realiza la autoridad de contralor en la jurisdicción, cabe notar que el mismo no difiere en gran medida del que se viene realizando para los otros tipos sociales regulados por la LGS. La salvedad es que, en el caso de utilizarse el contrato modelo sugerido por la DGSPJyRPC, naturalmente, las eventuales observaciones que se podrían generar son menores. En tal sentido, podemos concluir que la autoridad de contralor ejerce un pleno control de legalidad sobre la constitución de estas sociedades, en tanto que en la jurisdicción no se ha implementado aún el trámite y la firma digital.

En lo que hace al ejercicio de la autonomía de la voluntad por parte de los socios, y según se desprende de la práctica profesional, la misma se manifiesta principalmente en las cláusulas relativas al objeto, al capital social y a la disposición de las acciones. En general, se adopta el contrato modelo sugerido por la DGSPJyRPC y se realizan adecuaciones al mismo en las referidas cláusulas. La profesión contable procura lograr una adecuación entre el objeto social, el relacionamiento entre las categorías de las actividades que se desarrollan y el capital social. No se evidencian beneficios de considerar el monto de capital de dos salarios mínimos, atento a que, posteriormente, resulta necesario capitalizar los aportes irrevocables resultantes.

Respecto de los riesgos de utilización del marco legal de las SAS corresponde reconocer distintas realidades jurisdiccionales. El riesgo de una inadecuada utilización de la figura resultaría ser mayor en jurisdicciones tales como CABA. De todos modos, la profesión contable en la jurisdicción señala su preocupación hacia la posible utilización de esta figura legal con fines extrasocietarios.

Atento a lo expresado en referencia al tipo de emprendimiento que adopta la figura y las actividades económicas que se viabilizan en la práctica mercantil; las motivaciones señaladas; el ejercicio de la autonomía de la voluntad y la flexibilidad de las formas; el adecuado ejercicio del control de legalidad; y la necesidad de evitar la utilización de la figura con fines extra societarios, 
resulta pertinente realizar ciertas modificaciones legales o reglamentarias a efectos de fortalecer esta figura jurídica y evitar los riesgos señalados. Resultaría necesario, por ejemplo, restablecer el derogado art. $6^{\circ}$ de la LGS que establecía expresamente el control legal y fiscal por parte de los registros y otros organismos públicos, y reformular el art. 22 de la LACE indicando que el objeto social debe ser preciso y determinado, tal lo establecido en la LGS para sus tipos sociales regulados.

Ello redundaría en el incremento de las atribuciones de las autoridades de control, no solo en la constitución sino también en el funcionamiento de estas sociedades. Esta cuestión se encuentra en la actualidad planteada en el proyecto de reforma de la ley de SAS, la cual ya cuenta con media sanción del Senado de la Nación. Entre algunas de las modificaciones propuestas se encuentran las siguientes: la inscripción por parte de los emprendedores en un Registro específico, el traspaso del registro digital a la autoridad de contralor para su administración, control y mantenimiento exclusivo, la obligación de presentar los estados contables y la aplicación en forma supletoria de las disposiciones de la LGS.

\section{Referencias bibliográficas}

Abdala, M. (2018). Análisis crítico del proyecto de ley de creación de las sociedades por acciones simplificadas. Revista Prolegómenos. Derecho y Valores, 21(41), pp. 163-177.

Cho, J. y Lee E. (2014). Reducing confusion about grounded theory and qualitative content analysis: similarities and differences. The Qualitative Report, 19(64), pp. 1-20.

Duprat, D. (2017). Sociedades por acciones simplificadas (SAS). La Ley, (75), año LXXXI, pp. 1-8.

Elo, S. y Kyngas, H. (2007). The qualitative content analysis process. Journal of Advanced Nursing, 62(1), pp. 107-115.

Favier Dubois, E. y Spagnolo, L. (2018). Sociedad por acciones simplificada y empresa familiar: dos astros alineados. Monografías Ad Hoc.

Subsecretaría de Estadísticas y Censos, Ministerio de la Producción. (2020). Anuario Estadístico 2020. https://estadistica.lapampa.gob.ar/images/Archivos/AnuarioEstadistico/Anuario_Estadistico_2020-150321.pdf

Hsieh, H. y Shannon, S. (2005). Three approaches to Qualitative Content Analysis. Qualitative Health Research, 15(9), pp. 1277-1288.

Molina Sandoval, C. (2017). Sociedades por acciones simplificadas (SAS). La Ley, (75), año LXXXI, pp. 1-8.

Nissen, R. (2015). Curso de Derecho Societario. La ley 19.550 con las reformas efectuadas por la ley 26.994 y su adecuación al Código Civil y Comercial de la Nación. Hammunrabi.

(2018). La sociedad por acciones simplificada (SAS). El aporte societario del neoliberalismo a las sociedades off shore argentinas. FIDAS. 
Perciavalle, M. (2017). Nuevas sociedades de la Sección IV (simples o residuales). Erreius.

(2018). SAS. Ley comentada de las sociedades por acciones simplificadas. Teoría y práctica de su funcionamiento. Erreius.

Ramírez, A. (2018). El objeto social en la sociedad por acciones simplificada. La Ley, (72), año LXXXI, pp. 1-3.

(2019). La libertad contractual en la sociedad por acciones simplificada. Revista Argentina de Derecho Societario. Cita: IJ-DCCXL-143.

Saldaña, J. (2014). Coding and Analysis Strategies. En P. Leavy (Ed.) The Oxford Handbook of Qualitative Research. Oxford University Press.

Suozzi, L. (2017). Las novedosas sociedades por acciones simplificadas en el derecho argentino: riesgos a la luz del sistema de prevención de lavado de activos. Revista Lex Mercatoria. Doctrina, Praxis, Jurisprudencia y Legislación, (7), pp. 119-124.

Vitolo, R. (11 de octubre de 2017). SAS. Sus aspectos más relevantes y reglamentación de IGJ para su inscripción [Video]. YouTube. https://www.youtube.com/watch?v=iAb22L6zSbY

Umansky, S. (2018). Sociedades por acciones simplificadas: ¿Herramienta de apoyo al emprendedor o instrumento de fraude hacia terceros? Revista de la Facultad de Ciencias Económicas - UNNE, 21(2), pp. 101-118. 